\title{
Focus Marking in Amharic: Types and Coding Devices
}

\author{
Mosisa Asegid \\ School of Social Sciences and Humanities, Mekdela Amba University \\ P.O. Box 33, Mekane Selam, Ethiopia
}

\begin{abstract}
The term focus, like many of the jargons in the field of linguistics, has a number of uses. Pragmatically, however, it serves to provide a highlight on the relatively salient information in the given sentence. That is, in an utterance, focus, is used to highlight a specific constituent so as to make it noteworthy from the neighboring constituents. This highlight on the specific constituent is applied in order to emphasize on a piece of information inside that constituent, to contrast one piece of information with another, to introduce new information, to reinstate a presupposed information but dropped, to shift the listener's attention to another information, or topic. These different functions of focus can also be found in Amharic. Like their functions, they are also encoded in various ways. Thus, these different functions of focus and the ways in which they are encoded in Amharic are the core issues that are dealt within this paper.
\end{abstract}

Keywords: Pragmatic Focus, Amharic, Coding Devices

DOI: $10.7176 /$ JLLL/75-01

Publication date: January $31^{\text {st }} 2021$

\section{Introduction}

Even though it may not indicate the recent figure, Amharic is considered to have over seventeen million speakers (Meyer 2011). Due to its large number of speakers, it is also the second most populous Semitic language, after just Arabic (Hudson 1997). In addition to this, Amharic is the lingua franca and constitutionally recognized working language of Ethiopia (Endalew 2019), and, until recently, it served as a medium of instruction for primary grades in Public Education across the country.

Furthermore, Amharic, just like many African languages, is an interesting area for investigating typological universals of Focus phenomenon. It is a language which has a relatively simple morphological system of nouns but has a complex morphological system of verbs “...with a Subject Object Verb (SOV) constituent order" (Endalew 2019: 30). Subject and object (both direct and indirect) are inflected on the verb; however, subject agreement is obligatory, whereas object and indirect object agreement is often optional.

\section{Focus: Definition and Types}

The term focus has been defined variously by different scholars. The first systematic discussion of Focus was provided by Halliday (1967). In his discussion, the scholar mainly showed how prosodic means such as pitch and stress are used as a means of signaling focus in an utterance. Consequently, he suggested that information units are realized as tone groups. A tone group contains one obligatory component, namely a tonic segment.

Dik et al. (1981) discussed focus phenomenon from a typological perspective. In so doing, they presented a different classification of focus. Based on the work of Watters, these scholars described the distinction between shared and new information by providing examples of several languages. Accordingly, there are basically two types of focus namely contrast and non-contrast, which further can be classified into other sub-categories. Noncontrast focus consists of completives. The salient information in this type of focus is meant to fill-in a gap in the pragmatic information of the addressee (Dik et al. 1981: 60).

The second category of focus is contrast. Like the non-contrast one, it is further divided into two categories. The first type of contrast focus functions to specify a given information. They, in short, serve to select, expand, restrict, or replace the presupposed information of the hearer. The second type of contrast focus simply functions to indicate information which has equal value in the given discourse setting. Thus, they do not serve in order to specify a given constituent because every constituent in such constructions are not specific.

Generally, however, focus serves to provide "What is relatively the most important or salient information in the given setting" (Dik et al. 1981: 42). That is, in an utterance, focus, is used to highlight a specific constituent so as to make it noteworthy from the neighboring constituents in a clause or a sentence. This highlight on the specific constituent is applied in order to emphasize on a piece of information inside that constituent, to contrast one piece of information with another, to introduce new information, to reinstate a presupposed information but dropped, to shift the listener's attention to another information, or topic (Miller 2006: 511).

\section{Focus in Amharic}

Amharic is a South Semitic language and the working language of Ethiopia. Because it is a language with Subject Object Verb (SOV) constituent order, there is no morphological means of controlling focus; hence, it is controlled 
by pragmatics; that is, encoding the focus explicitly is not always obligatory (Girma and Meyer 2008).

As it was noted in the previous sections, focus refers to the new information asserted, questioned, etc. in relation to what has been presupposed by the listener. It, thus, based on the informational content of the sentence, answers the relevant $w h$ - question that could be raised depending on that piece of information in the Focused constituent. Hence, in (1a):

1.

(a) hule bə- toganannə-n k'utr ine nabərk-u

Every time PREP-meet.asfor.ACC 1S. present.PFV.

ja-taksi ja-mkafl-əw ahun gin abəbə kafal-ə

GEN.taxi REL.pay.1S.ACC now but Abebe pay.PFV.3SM ${ }^{1}$

'Every time we meet, I was the one who pays for the taxi, but this time, Abebe paid.'

Abebe represents the focus. It indicates the variable in the presupposition ' $\mathrm{X}$ paid for the taxi'. Here, the focus is expressed through a prosodic means of stress and a relative higher pitch placed on the salient information. Consequently, Miller (2006: 511b) states "Contrastiveness is manifested principally by the placement of higher pitch and stronger stress on the focus of contrast".

Moreover, there are other devices which are used to mark Focus in Amharic. These devices can be morphological elements, discourse particles, or special syntactic structures. The example in (1a), for instance, can be summraised as Abebe iko now ja-taksi ja-kəfalo-w 'It is Abebe who paid for taxi'. Here, the word ordering is changed from SOV in (1a) to SVO in the latter example. Thus, word ordering, is another way in which focus is marked in Amharic.

Amharic also uses the enclitic $-\mathrm{mm}$ as a morphological means of marking focus: Consider the following examples:

2. (a). Mosisa-mm inklf ji-wad-al

Mosisa.FOC sleep JUS.like.3SM

'Mosisa too likes to sleep' (lit. Mosisa.Foc likes sleep)

In (2a), Mosisa is an example of topic marking of a sentence. Hence, in the context of the above utterance, the enclitic $-m m$ presupposes that the interlocuters were talking about another animate [+animate] topic (X) who likes to sleep. The speaker, thus, based on the shared knowledge regarding this animate entity, entails that Mosisa likes to sleep as much as X likes to sleep. This example however does not generalize about the usage of the enclitic $-m m$ as a focus marker. In fact, Girma and Meyer (2008:609) state that "Although the enclitic element - $m m$ follows the topicalized constituent, it does not itself have the function of a topic marker. The enclitic element $-m m$ can also be found cliticized to constituents which are not topics in positions other than sentence-initial".

In line with the above statement, we can, for instance, change the position of the enclitic - $m m$ in (2a) so as to apply it into the object final position: Mosisa inklf-mm jiwad-al 'Mosisa likes sleeping, too'. This utterance, unlike the example in (2a), presuposses that the participants were disussing about a similar topic, which is 'Mosisa'. The focus of their discussion, however, is said to be revolving around 'the thing/s which Mosisa like/s'. This can be represented as 'Mosisa likes both $X$ and $X$ [in which the latter X represents 'sleeping'].

Another way in which Amharic marks focus is through the particles $\dot{i} k o$ and $b \dot{t} \ddot{c} c ̌ a . ~ i k k o$ can stand on its own in a sentence following the constituent it modifies. However, this particle, when it occurs after the topic and followed by the auxilary nəw, creates cleft and pseudo-cleft constructions. The following examples illustrate this point further:

3. (a) abəbə lïj-u-n mata-w

Abebe boy-DEF-ACC kick-PFV.1SM

'Abebe kicked the boy'

(b) ababə iko nəw lijj-u-n ja-mota-w

Abebe-FOC AUX boy-DEF-ACC REL-kick.1SM

'It was Abebe who kicked the boy'

\begin{tabular}{ll}
\hline${ }^{1}$ List of Abbreviations \\
$1,2.3$ & First, Second, and Third Person \\
AUX & Auxiliary \\
DEF & Definite \\
FOC & Focus \\
JUS & Jussive \\
GEN & Genitive \\
M & Masculine \\
NEG & Negative/Negation \\
PFV & Perfective \\
PL & Plural \\
PREP & Preposition \\
REL & Relativizer \\
RELP & Relative Pronoun \\
S & Singular
\end{tabular}




$$
\begin{gathered}
\text { abəbə lij-u-n məta-w iko } \\
\text { Abebe boy-DEF-ACC kick-PFV.1SM FOC } \\
\text { 'Abebe kicked the boy' }
\end{gathered}
$$

(3a) shows what Dik et al. (1981: 44) calls 'Focus neutral assertion'. If the topic Abebe is said with a stress and a relatively higher pitch than the other constituents in the sentence, it would presuppose that the speaker is emphasizing on the unexpectedness of the fact that Abebe actually hit someone. In ( $3 \mathrm{~b})$, on the other hand, there is a contrast in terms of who the listener presupposed to be the doer of the action and what the speaker knows about the doer of the action. Furthermore, (3c) interestingly denotes at least two different presuppositions which can be understood based on the discourse cotext. These constructions are shown in the following illustration which are adopted from Dik et al. (1981):

I. Abebe kicked the boy \{you would not believe it! (3a)

II. Abebe kicked the boy not Kebede, as you seem to assume] (3b)

III. Abebe kicked the boy as he said he would\} (3c)

IV. Abebe kicked the boy \{he did not 'hug/kiss/ etc.' him, as we thought he would $\}$ (3c)

The other possible Focus coding device in Amharic is the particle ' $b \ddot{t} \check{c} \check{c} a$ '. This discourse particle can have multiple function in the Amharic language. As a Focus particle, however, it can have an equvalent function as the English word 'only'.
4. (a) mosisa bičča timhrt-u
laj atəkor-ə

Mosisa only education.DEF PREP. focus-PFV-3SM

(b) mosisa timhrt-u laj bïčča atəkor-ə

'Only Mosisa Focused on his education.'

mosisa education-DEF PREP. only focus-3SM

'Mosisa focused only on his education.'

The examples above illustrate how the particle 'bïčca' can be used as a contrastive Focus marker. The example in (4a) presupposes that even though there are other individuals who should be focusing on their education, it is only Mosisa who is doing so. Logically, this proposition can be written as 'only person X is having a focus on education, and no one else' $\{\mathrm{X}=$ Mosisa $\}$. On the other hand, the example on (4b) presupposes that even though there are other things/activities/events that the topic/subject could be focusing on, he only focused on his education. This statement can be summarized as: 'Mosisa focused only in $X$ and not in $Y$ ' \{this time, $\mathrm{X}=$ education .

A combination of focus particles and syntactic constructions can also be used to indicate contrastive Focus.

5. (a) lij-očč-u kuas mačawat indzi majat

Boy-PL.DEF ball to.play RELP to.watch

aj-wad-u-m

NEG-like-PFV.3PL.

'The boys only like playing soccer, not watching it'

The above example illustrates how focus particles such as indzi can be combined with other morphological and syntactic constructions such as aj-, and -um to restrict the meaning of the proposition. The first independent clause has the function of filling in the already given or known information; the second dependent clause, however, is counter-assertive in its nature since it is presupposed that the speaker is substituting for information which he/she presumed the hearer asserted in previous utterance.

\section{Conclusion}

The article investigated the distribution of pragmatic focus phenomenon and the ways in which it is manifested in Amharic. Hence, it was observed that there are various coding devices which are used to mark salient information in the language. Phonological means such as stress and higher pitch, morphological particles such as the enclitic $m m$, disourse particles such as bičča and $i k o$, and the combination of all of these devices with syntactic elements are some of the ways in which focus is marked in the Amharic language. Be it for the purpose of filling-in, expanding, restricting, or even replacing a given piece of information contained in the pragmatic information of the hearer, the speaker applies the above-mentioned focus marking strategies merely to make a given constituent salient. This salient constituent, in return, carry new information that has not been presented in the discourse context until the point of the utterance.

\section{References}

Dik, Simon, Hoffmann, Maria E., Jong, Jan R. de, Djiang Sie Jng, Stroomer, Harry and Vries, Lourens de. "On the typology of focus phenomena." Teun Hoekstra, Harry van der Hulst \& Michael Moortgat. Perspectives on Functional Grammar. Dordrecht: Foris, 1981. 41-74.

Endalew, A. (2019). Typological Comparison of Relativization in Amharic and Ezha. Journal of Universal Language, 29-52. doi:10.22425/jul.2019.20.2.29

Girma, A. Demeke and Ronny Meyer. "The enclitic -mm in Amharic: reassessment of a multifunctional 
morpheme." Linguistics 46.3 (2008): 607-628.

Halliday, M. "Notes on transitivity and theme in English." Journal of Linguistics 3 (1967): 37-81.

Hudson, G. (1997). Amharic and Argobba. In R. Hetzron, The Semitic Languages (pp. 457-485). New York: Rotledge.

Meyer, R. (2011). Amharic. In S. Weininger, \& et al., The Semitic Languages (pp. 1178-1212). Berlin: Walter de Gruyter.

Miller, J. "Focus." Brown, Keith. Encyclopedia of Language and Linguistics. Aucklnd: Elsevier, 2006. $511 \mathrm{a}-519 \mathrm{~b}$. 